\title{
KOMPETENSI PEDAGOGIK GURU PENDIDIKAN AGAMA BUDDHA BERLANDASKAN MORALITAS (KAJIAN KITAB DHAMMAPADA)
}

\author{
Sugianto $^{1}$ \\ STABN Sriwijaya Tangerang Banten \\ sugianto@stabn-sriwijaya.ac.id
}

\begin{abstract}
The duties and responsibilities of the Buddhist education teacher can only be done by teachers with expertise in education and Buddhism. The story of the silaVamsa Jataka No. 362, gives the assertion that morality is more valuable than intelligence. Morality is the basis the implementation of the teaching profession. Analyzing the values of morality in the Dhammapada with library research. serve as the foundation for the Buddhist education teachers

Sila (virtues) is a spark of the mind to avoid actions that are not well and do good deeds. Right speech, right action, and right livelihood categorized in sila. People will not do something that does not want him to be treated with such actions.

Dhammapada is aspects of the Dhamma, consists of four levels: teaching to build prosperity and happiness of the concrete human relations, teaching for the present life and future, theoretical framework to achieve liberation, the statements of people who have reached the level of sanctity and realize Nibbana. Dhammapada teaches the simplicity of life, sense of control, confidence and spirit so as not controlled by lust, controlling speech. Avoiding false speech, dirty, slander or nonsense, controlling emotions, curb anger with love.

Buddhist education teacher pedagogical competence is the ability to master the characteristics of learners; master the theories and principles of learning; organizes educational learning; utilizing information and communication technologies; facilitate the development of potential learners; communicate in learning activities; conduct assessment and evaluation; utilizing the results of the assessment and evaluation of learning; reflective to increase the quality of learning. Pedagogical competence based on the morality is the ability of teachers to manage classes with the apply of right speech and right action as well as make the teacher as a form of right livelihood.

Kata Kunci: Kompetensi Pedagogik, Guru Pendidikan Agama Buddha, Moralitas Buddhis, Dhammapada

\footnotetext{
${ }^{1}$ Dosen Pendidikan Agama Buddha Jurusan Dharmacarya di Sekolah Tinggi Agama Buddha Negeri Sriwijaya Tangerang Banten.
}

Jurnal Vijjacariya 


\section{Pendahuluan}

Guru Pendidikan Agama Buddha (PAB) bertugas mengajarkan, menyampaikan dan menyebarkan Buddha Dhamma. Guru PAB mendidik, mengajar dan melatih peserta didik tentang cara-cara hidup yang baik dan benar untuk mencapai kebahagiaan sejati. Mendampingi tumbuh kembang peserta didik. Mengarahkan peserta didik pada hal-hal yang positif. Menilai dan mengevaluasi perkembangan belajar peserta didik. Tugas dan tanggung jawab yang hanya bisa dilakukan oleh guru dengan keahlian ilmu agama Buddha dan ilmu pendidikan.

Perkembangan ilmu pengetahuan dan teknologi berpengaruh pada tuntutan masyarakat terhadap pendidikan agama Buddha. Perkembangan ilmu pengetahuan dan teknologi juga memberi efek pada model pendidikan agama Buddha. Guru PAB tidak bisa menghindari kemajuan ilmu pengetahuan dan teknologi. Sumber belajar yang melimpah dalam bentuk buku atau ebook telah memudahkan guru dan peserta didik mendapatkan ilmu. Guru dapat mengakses internet dan memanfaatkannya untuk mendapatkan informasi tentang model, metode, dan strategi belajar; perkembangan kurikulum, teori-teori belajar.

Guru PAB yang profesional mampu mengelola pembelajaran dengan baik. Menguasai karakteristik peserta didik, memilih materi yang sesuai dengan perkembangan dan kebutuhan peserta didik adalah hal mendasar yang harus dikuasia oleh guru. Menguasai teori-teori belajar. Update dengan perkembangan kurikulum. Melaksanakan pembelajaran yang mendidik. Mengembangkan potensi siswa. Memanfaatkan teknologi informasi dan komunikasi untuk mendudukung pembelajaran. Menilai dan mengevaluasi dengan benar, serta menindaklanjuti untuk tujuan peningkatan mutu pembelajaran.

Kemampuan-kemampuan di atas perlu dilandasi dengan moralitas. Kualitas batin yang mengarahkan pada ucapan, perbuatan, dan matapencaharian benar. Sehingga profesi ini dilaksanakan atas dasar kebenaran. Tanpa moralitas, guru menimbulkan banyak masalah. Ucapan, sikap dan perbuatan yang cenderung ke halhal negatif. Muncul ketidaksesuaian antara ucapan dengan praktik ajaran dalam 
keseharian guru. Ajaran Buddha hanya dijadikan teori. Pengajaran dilakukan dengan cara-cara salah. Secara umum, guru melakukan penghidupan yang salah.

Moralitas sebagai landasan pelaksanaan profesi guru berpengaruh pada cara guru berucap dan berbuat. Kasus kekerasan guru terhadap anak dapat dihindari. Ucapan-ucapan guru yang kasar, memfitnah, omong kosong atau berdusta tidak terjadi. Kecurangan-kecurangan guru dalam penilaian dan evaluasi demi motif tertentu tidak dapat dilakukan guru yang bermoral. Menjaga kehormatan profesi dengan meningkatkan kinerja dan bertindak sesuai dengan etika profesi. Membina diri menjadi guru profesional berdasarkan hasil refleksi.

Kisah Jataka dalam Silla-vamsa Jataka No. 362, memberikan penegasan bahwa moralitas lebih berharga dari kepandaian. Kepandaian atau keterampilannya tidak mampu mencegah sanksi berupa celaan, hinaan, sanksi atau hukuman yang lainnya ${ }^{2}$. Berawal dari pemikiran itu, analisis nilai-nilai moralitas dilakukan untuk dijadikan landasan kerja guru PAB. Peneliti tertarik mengkaji kitab Dhammapada yang sudah populer di masyarakat Buddhis. Kitab Dhammapada mudah dipahami karena tersusun atas syair-syair pendek. Kajian yang digunakan adalah studi kepustakaan (library research $)^{3}$.

\section{Kajian Teori}

1. Nilai-Nilai Moralitas (S̄̄la) Di Kitab Dhammapada

Sila (virtues) diartikan sebagai cetusan pikiran yang hadir dalam diri seseorang untuk menghindari perbuatan-perbuatan yang tidak baik dan melaksanakan perbuatan yang baik. "It is the states beginning with volition present in one who abstains from killing living things, etc., or in one who fulfils

\footnotetext{
${ }^{2}$ http://www.samaggi-phala.or.id/tipitaka/silavimamsa-jataka-2/

${ }^{3}$ Kajian kepustakaan tidak sekedar menemukan dan meringkas data dan menggambarkan kesimpulan dari itu. Tapi data informasi dianalisis dan dikaitkan atau dihubungkan. “...as information analysis and synthetis, focusing on findings and not simply bilbiographic ciations, sunmmarizing the substance of literature and drwaing conclusions from it." (Randolph (2009) dalam Punaji Setyosari, (2010) hal. 85.
} 
the practice of the duties." " Ucapan benar, perbuatan benar, dan penghidupan benar dalam Jalan Tengah berunsur delapan dikategorikan dalam aspek sīla ${ }^{5}$. Sila juga dapat dilakukan dengan beberapa cara, yaitu 1) menghindari pembunuhan, 2) menghindari mengambil barang yang tidak diberikan, 3) menghindari ketidaksucian, 4) menghindari ucapan salah, 5) menghindari fitnah, 6) menghindari ucapan kasar, 7) menghindari gosip, 8) seorang yang menjauhi merusak benih, 8) menghindari tontonan, tarian, musik, dan hiburan, 9) menghindari memakai karangan bunga, pengharum, kosmetik, dan perhiasan, 10) menghindari tempat tidur yang tinggi dan lebar, 11) menghindari menerima emas dan perak, $\mathrm{dsb}^{6}$. Sìla menyadarkan orang untuk tidak berbuat sesuatu yang baginya tidak mau diperlakukan dengan perbuatan semacam itu....virtues such as non-violence and compassion, and the Buddhist version of the 'Golden Rule' counsels us not to do anything to others we would not like done to ourselves ${ }^{7}$.

Secara ontologi, Dhammapada sebagai bagian, aspek dari Dhamma ${ }^{8}$, yang terdiri dari empat level. Level pertama, ajaran untuk membangun kesejahteraan dan kebahagiaan hubungan manusia yang konkrit. Level kedua ajaran untuk kehidupan sekarang dan akan datang. Level ketiga, kerangka teori untuk mencapai pembebasan. Level keempat, pernyataan-pernyataan orang yang sudah mencapai tingkatan kesucian hingga merealisasi Nibbana.

Pikiran menjadi pemimpin atau pelopor ${ }^{9}$. Pikiran baik akan mempelopori ucapan dan perbuatan yang baik. Mengarahkan pada kesederhanaan hidup, pengendalian indera, keyakinan dan semangat agar tidak dikuasai nafsu jahat ${ }^{10}$.

\footnotetext{
${ }^{4}$ Nanamoli, 2010:11

${ }^{5}$ SN.V.Sacca Samyutta.

${ }^{6}$ Brahmajala Sutta, Digha Nikaya

${ }^{7}$ Damien Keown dalam buku Buddhist Ethic a Very Short Introduction

${ }^{8}$ http://www.accesstoinsight.org/tipitaka/kn/Dhammapada/Dhammapada.intro.budd.html

${ }^{9}$ Dhammapada1.1-2

${ }^{10}$ Dhammapada1.8
} 
Salah satu jenis ucapan benar adalah ucapan ramah dalam menyuarakan kata-kata yang akan mendatangkan manfaat besar ${ }^{11}$. Pada situasi lainnya, batin yang berkualitas ditandai dengan keteguhan dan ketenangan menghadapi pujian maupun celaan ${ }^{12}$. Mampu mengendalikan ucapan dan tenang menghadapi kondisi menyenangkan dan tidak menyenangkan ${ }^{13}$.

Moralitas lebih dulu dilatih untuk diri-sendiri sebelum diajarkan pada orang lain ${ }^{14}$. Berhasil menjaga diri, membebaskan dari kemerosotan moral, menghindari perbuatan jahat. Menghindari hidup salah dan tercela dengan semangat mengendalikan indera. Tidak membiarkan indera terbuai. Senantiasa menjaga kewaspadaan, serta menjaga pengaulan yang baik ${ }^{15}$. Tidak mencari-cari kesalahan orang lain, mengembangkan cinta kasih, mengendalikan tingkah laku dan ketenangan batin ${ }^{16}$. Menghindari ucapan dusta, kotor, fitnah ataupun omong kosong. Mengendalikan emosi, mengekang kemarahan dengan cinta kasih ${ }^{17}$. Mampu membedakan kebenaran dengan kesalahan. Bijaksana menilainya atas dasar kejujuran, obyektif dan sesuai kebenaran Dhamma ${ }^{18}$. Memutuskan dengan adil $^{19}$ agar tidak ada pihak yang dirugikan. Menimbang dengan bijak yang baik dan buruk, lalu menjauhi perbuatan buruk dengan kebijaksanaan luhur ${ }^{20}$. Kemoralan menimbulkan ketenangan karena tidak khawatir terhadap akibat perbuatannya $^{21}$.

\section{Kompetensi Pedagogik Guru PAB}

Guru adalah pendidik profesional yang bertugas mendidik, mengajar, membimbing, mengarahkan, melatih, menilai, dan mengevaluasi peserta $\operatorname{didik}^{22}$.

${ }^{11}$ Dhammapada3.52

${ }^{12}$ Dhammapada5.81

${ }^{13}$ Dhammapada5.83

${ }^{14}$ Dhammapada12.158-159

${ }^{15}$ Dhammapada13.167

${ }^{16}$ Dhammapada14.185

${ }^{17}$ Dhammapada17.223

${ }^{18}$ Dhammapada 19.257

${ }^{19}$ Dhammapada 19.256

${ }^{20}$ Dhammapada 19.269

${ }^{21}$ Dhammapada 9.124

${ }^{22}$ UU No. 14 Tahun 2005 tentang Guru dan Dosen 
Pendidik profesional butuh keahlian, keterampilan dan pengetahuan; Kepandaian khusus untuk menjalankannya, dan mengharuskan ada pembayaran untuk melakukannya ${ }^{23}$. Pekerjaan profesional memiliki kode etik ${ }^{24}$ sebagai sumber etika, aturan, sopan santun, atau tata susila; suatu hal yang berhubungan dengan kesusilaan dalam mengerjakan pekerjaan ${ }^{25}$. Guru yang mencintai profesi bekerja dengan sepenuh hati. Totalitas menjadikan diri sebagai guru sejati: a) terdidik dengan baik (well-educated); b) terlatih dengan baik (well-trained); c) mendapat penghargaan yang baik (well-paid); d) terlindungi dengan baik (well-protected); e) terkelola dengan baik (well-manager) ${ }^{26}$.

Kompetensi pedagogik yang dikuasai Guru PAB sesuai dengan Permendiknas No. 16 Tahun 2007. Mampu menguasai karakteristik peserta didik; menguasai teori belajar dan prinsip-prinsip pembelajaran yang mendidik; mengembangkan kurikulum PAB; menyelenggarakan pembelajaran PAB yang mendidik; memanfaatkan teknologi informasi dan komunikasi untuk kepentingan PAB; memfasilitasi pengembangan potensi peserta didik; berkomunikasi secara efektif, empatik, dan santun dalam kegiatan pembelajaran; menyelenggarakan penilaian dan evaluasi proses dan hasil belajar; memanfaatkan hasil penilaian dan evaluasi untuk pembelajaran; reflektif untuk peningkatan kualitas pembelajaran.

\section{Pembahasan}

Ucapan benar, perbuatan benar, dan penghidupan benar adalah tiga unsur yang menjadi bagian dari aspek moralitas. Kompetensi pedagogik guru yang berlandaskan moralitas adalah kemampuan guru dalam menerapkan ucapan benar, perbuatan benar, dan penghidupan pada hal-hal yang menjadi bagian dari kompetensi pedagogik.

\footnotetext{
${ }^{23}$ Kamus Besar Bahasa Indonesia (KBBI), (2008:1104)

${ }^{24}$ Barnawi dan Mohamad Arifin, 2012. Hal. 52

25 ibid

${ }^{26}$ Sembiring, 2008. Hal. 34
} 
1. Penguasaan Karakteristik Peserta Didik

Guru PAB memahami karakteristik peserta didik dari berbagai aspek. Guru perlu tahu aspek fisik, intelektual, sosial-emosional, moral, spiritual, dan latar belakang sosial-budaya peserta didik. Keramahan guru, membuat peserta didik nyaman berbagi informasi. Kesediaan guru menjaga rahasia peserta didik menjadi jaminan bagi peserta didik memberikan informasi kepada guru. Kejujuran yang menjadi sumber kepercayaan guru dari peserta didik. Guru menghindari cara-cara yang salah yang membuat peserta didik menjadi tidak nyaman, takut, atau terpaksa dalam bercerita. Tidak mengancam peserta didik sebaliknya dengan mengembangkan cinta kasih. Guru membina hubungan positif dengan peserta didik.

Ada peserta didik yang memiliki kecerdasan yang kurang. Tugas guru membantu meningkat kecerdasan peserta didik, bukan mencari-cari kesalahan peserta didik. Memotivasi dengan ramah agar peserta didik rajin belajar. Menghindari ucapan-ucapan yang dapat merendahkan kepercayaan diri peserta didik.

2. Penguasaan Teori Belajar dan Prinsip Pembelajaran.

Teori-teori belajar digunakan sesuai dengan situasi di lingkungan kelas serta karakteristik peserta didik. Guru memilih teori belajar yang tepat, sesuai dengan prinsip-prinsip pembelajaran. Perhatian dan motivasi, keaktifan, keterlibatan langsung, pengulangan, tantangan, balikan dan penguatan, dan perbedaan individual adalah bagian dari prinsip-prinsip pembelajaran yang dikuasai guru. Strategi, metode dan teknik pembelajaran dipilih secara tepat agar menciptakan pembelajaran yang kreatif.

3. Penguasaan Pembelajaran yang Mendidik

Komponen-komponen pembelajaran mencakup kemampuan guru, karakeristik siswa, tujuan pembelajaran, sumber belajar dan ketersediaan failitas pendukung kegiatan belajar disusun lengkap. Kegiatan pembelajaran dapat diadakan dalam kelas, laboratorium, maupun lapangan dengan memperhatikan standar keamanan bagi guru dan peserta didik. Cinta kasih 
dan kasih sayang guru dilakukan dengan kesediaan menjaga keselamatan peserta didik selama proses pembelajaran. Media dan sumber belajar dibutuhkan untuk mencapai tujuan pembelajaran. Media belajar memudahkan menjelaskan materi. Sumber belajar dibutuhkan guru agar tidak asal berbicara kepada peserta didik. Guru PAB berani mempertanggungjawabkan kebenaran dari yang diucapkan dan dilakukan.

Ucapan dan perbuatan guru PAB selama pembelajaran dicontoh peserta didik. Perilaku guru yang bermoral adalah sumber pembelajaran peserta didik. Guru menjadikan diri sebagai contoh dengan ucapan-ucapan dan perilaku guru yang baik. Tidak ada kata-kata kasar. Guru menjelaskan materi dengan memilih kata-kata yang sopan. Materi disampaikan dari sumber yang akurat untuk menghindari ucapan yang tidak beralasan dan terjamin kebenarannya. Kesulitan peserta didik dalam memahami materi, diupayakan solusinya. Guru tidak mudah marah dalam menghadapi kelas yang kurang memahami materi, tidak mencari kesalahan peserta didik, sebaliknya memberikan motivasi kepada peserta didik dengan berbagi model belajar sesuai karakteristik peserta didik. Aktifitas guru dalam kehidupan sehari-hari menjadi inspirasi peserta didik.

4. Penguasaan Teknologi Informasi dan Komunikasi

Teknologi informasi dan komunikasi (TIK) dimanfaatkan guru dalam mengelola kegiatan pembelajaran. Internet merupakan teknologi yang memberikan banyak informasi dan sekaligus memberikan layanan komunikasi. Keterampilan guru menggunakan internet untuk mencari bahan ajar, media ajar, dan sumber ajar menjadi efektif dan efisien. Pemanfaatan internet yang benar memberikan berkah dan manfaat bagi guru.

Moralitas mencegah guru dari perilaku salah dalam menggunakan internet. Guru tidak memposting hal-hal yang negatif atau mendownload hal-hal yang tidak ada kaitannya dengan kepentingan profesi atau menggunakan internet untuk hal-hal yang tidak berfaedah. Memanfaatkan 
internet untuk mendukung pembelajaran, memanfaatkan email untuk pengumpulan tugas dari peserta didik, bimbingan peserta didik jarak jauh.

5. Penguasaan Pengembangan Potensi Peserta Didik

Guru yang kreatif mengelola kelas tidak semata-mata untuk meningkatkan pengetahuan peserta didik. Guru juga sekaligus mengarahkan pada pengembangan potensi peserta didik. Potensi peserta didik dikembangkan melalui kegiatan pembelajaran dan di luar pembelajaran. Pengembangan potensi melalui kesempatan menunjukan bakat peserta didik, seperti menyanyi, bermain musik, menari, baca paritta atau Dhammapada, bahkan Dhammadesana.

Guru memfasilitasi pengembangan potensi peserta didik dengan menggunakan bahasa yang benar, agar peserta didik antusias dalam mengembangkan potensi. Pengembangan potensi dilakukan secara adil. Bagi peserta didik yang ingin melatih diri dalam kehidupan non duniawai sebagai samanera atau samaneri, guru PAB pantas memberikan izin.

6. Penguasaan Strategi Komunikasi dalam Pembelajaran

Kelas merupakan tempat yang paling sering guru dengan peserta didik bertemu. Komunikasi yang baik selama proses pembelajaran berpengaruh terhadap keberhasilan pendidikan. Penguasaan strategi komunikasi bagi guru PAB selama proses pembelajaran menentukan cara guru dalam memilih dan menentukan cara dan bentuk komunikasi dengan peserta didik. Komunikasi yang efektif mudah dipahami peserta didik. Bahasa mudah dipahami, tidak berbelit-belit, menggunakan contoh sehari-hari. Ramah, tidak menggunakan kata-kata kasar, kotor, atau menghina peserta didik atas dasar apapun.

Komunikasi yang baik membantu keberhasilan pembelajaran. Komunikasi antara guru dan peserta didik dilakukan secara lisan, tertulis, secara langsung atau tidak langsung. Komunikasi dilakukan saat guru membuka pelajaran, saat pelajaran berlangung, dan ketika pembelajaran diakhiri. Terjadi ketika guru membuka pelajaran, menjelaskan materi, bertanya, memotivasi, menguatkan, menjawab pertanyaan peserta didik, 
menyimpulkan materi, serta memberikan saran kepada peserta didik. Komunikasi juga terjadi ketika guru membimbing peserta didik secara individu atau kelompok.

Komunikasi yang baik menciptakan dan mengembangkan suasana pembelajaran yang kondusif. Saat guru sudah tidak menjadi sumber tunggal ilmu, komunikasi antara guru dengan peserta didik menjadi lebih bervariasi. Peserta didik mendapatkan kesempatan lebih banyak berkomunikasi dengan guru maupun sesama peserta didik. Guru tidak bisa memonopoli komunikasi di kelas. Guru menjadi pendengar yang baik, tidak menyela ketika ada peserta didik yang sedang berbicara.Mendengarkan peserta didik yang sedang berbicara di kelas adalah sikap yang baik dari seorang guru. Jadi, ketika guru dan peserta didik mendapatkan kesempatan berkomunikasi yang baik, pembelajaran menjadi kondusif.

7. Penguasaan dalam Penilaian dan Evaluasi

Guru menentukan aspek-aspek, prosedur penilaian dan evaluasi serta mengembangkan instrumen penilaian dan evaluasi. Penilaian dan evaluasi dilakukan secara obyektif. Guru tidak membuat penilaian atas dasar status sosial, ekonomi, gender, atau fisik. Penilaian dilakukan secara jujur, tidak dilebih-lebihkan atau dikurangi nilainya. Guru tidak memanipulasi nilai atau menjual nilai untuk keuntungan finansial guru.

Guru menyusun hasil penilaian dengan rapi dan menyimpan di tempat yang aman. Kerahasiaan hasil penilaian terjaga. Hanya orang-orang yang berkepentingan yang dapat mengetahuinya. Lembar kerja dikembalikan kepada peserta didik sebagai bahan evaluasi diri. Selain itu, hasil penilaian menjadi bahan atau dasar melakukan tindak lanjut bagi guru.

Hasil penilaian dan evaluasi juga disampaikan kepada pemangku kepentingan, seperti wali kelas, dan orangtua. Guru PAB dapat menjalin komunikasi yang baik dengan wali kelas, dan orang tua untuk membahas hasil tersebut demi perbaikan atau peningkatannya prestasi belajar. Guru 
PAB mengkomunikasikan perkembangan belajar peserta didik kepada walikelas atau dengan orangtua peserta didik.

Hasil evaluasi belajar peserta didik bagi guru PAB bemanfaat sebagai bahan refleksi. Refleksi diri dilakukan guru PAB terhadap hasil pencapaian belajar peserta didik. Pada tahap ini, kejujuran guru menentukan hasil hasil refleksi. Nilai-nilai moralitas penilaian. Guru berani mengakui kesalahan masa lalu, kelemahan diri dan bertekad untuk memperbaki serta tidak diulang. Guru PAB penuh semangat, disiplin, dan tekun melakukan perbaikan secarfa konsisten. Jadi, refleksi bagi guru bermanfaat untuk perbaikan dan pengembangan mutu pembelajaran PAB di waktu selanjutnya.

\section{Simpulan}

Guru PAB adalah pendidik profesional yang memiliki tugas untuk mendidik, mengajar, melatih, membimbing, mengarahkan dan mengevaluasi peserta didik pada pendidikan formal. Kode etik profesi bagi guru PAB menjadi panduan atau pedoman kerja agar tidak melakukan hal-hal yang buruk. Kode etik memandu guru PAB berkerja dengan benar tanpa melanggar norma-norma atau aturan hukum. Kompetensi pedagogik guru PAB adalah kemampuan guru mengelola kelas agar menjadi tempat yang kondusif untuk belajar. Kemampuan yang terkait penguasaan karakteristik peserta didik, teori dan prinsip pembelajaran, pembelajaran yang mendidik, pengembangan potensi peserta didik, penguasaan teknologi komunikasi dan informasi, strategi komunikasi dalam pembelajaran, penilaian dan evaluasi. Kemampuan yang berguna dalam proses pembelajaran pendidikan agama Buddha.

Nilai-nilai moralitas Buddhis adalah ajaran dari Buddha Gotama yang meliputi praktik ucapan benar, perbuatan benar, dan mata pencaharian benar. Menghindari hal-hal yang buruk dan mengembangkan hal-hal yang baik. Kualitas batin yang luhur untuk mencegah orang berbuat jahat, dan mengarahkan orang berbuat baik. Melakukan hal-hal yang baik untuk diri sendiri dan orang lain. Tidak melakukan hal-hal yang merugikan diri sendiri dan orang lain. Salah satu sumber 
ajaran moralitas dapat ditemukan di kitab Dhammapada. Kompetensi pedagogik guru PAB yang berlandaskan moralitas berupa kemampuan guru dalam mengelola kelas untuk menciptakan pembelajaran $\mathrm{PAB}$ yang kondusif dengan penerapan ucapan benar, dan perbuatan benar adalah indikator dari moralitas guru PAB. Moralitas menjadikan guru sebagai profesi yang terhormat. Moralitas melandasi cara kerja guru, menjadikannya sebagai bentuk matapencaharian benar, yang memberikan manfaat bagi guru maupun peserta didik.

\section{DAFTAR REFERENSI}

Barnawi dan Mohamad Arifin. Etika dan Profesi Kependidikan. Jogyakarta: Ar-Ruzz Media, 2012.

Bodhi, Bhikkhu. Khotbah-khotbah Berkelompok Sang Buddha Buku Tiga Khandhavagga Samyutta Nikaya. Jakarta: Dhammacitta Press, 2010.

Buddhaghosa. The Path of Purification: Visuddhimaga. Diterjemahkan oleh: Nanamoli. Kandy: Buddhist Publication Society, 2010.

Departemen Pendidikan Nasional. Kamus Besar Bahasa Indonesia Edisi Empat. Jakarta: Gramedia Pustaka Utama, 2008

Keown, Damien. Buddhist Ethics a Very Short Introduction. England: Oxford University, (tanpa tahun).

Permendiknas No. 16 Tahun 2007 tentang Standar Kualitifaksi Akademik dan Kompetensi Guru.

Sembiring, M. Gorki. 2008. Menjadi Guru Sejati. PT. Galangpress Media Utama

Tanpa nama. Sīla. http://www.accesstoinsight.org/ptf/dhamma/sila/index.html (diakses pada tanggal 13 Desember 2012)

Tanpa Tahun. The Dhammapada: The Buddha's Path of Wisdom. Terjemahan oleh Acharya Buddharakkhita. http://www.accesstoinsight.org/tipitaka/an/an08/an08.054.than.html. (diakses pada bulan Desember 2012).

Tim Penyusun. Silavimamsa-jataka. http://www.samaggiphala.or.id/tipitaka/silavimamsa-jataka-2/ (diakses pada bulan Desember 2012). Medan: Indonesia Tipitaka Center.

Undang-Undang RI Nomor 14 Tahun 2005 tentang Guru dan Dosen.

Walshe, Maurice. Khotbah-khotbah Panjang Sang Buddha Digha Nikaya. Diterjemahkan oleh Team Giri Manggala Publication Team Dhammacitta Press. Jakarta; DhammaCitta, 2009.

Zed, Mestika. Metode Penelitian Kepustakaan. Jakarta: Yayasan Obor Indonesia, 2004. 